\title{
Responding to needs and pressures - from a distance
}

$E T$ is driven only in part by editorial intent. I meet and hear from many people, and discuss many possible articles and projects with them, some of which mature swiftly and some more gently, while others gestate like an elephant or never get going at all. The key driving force is, however, from outside, from those who send in all kinds of material for all sorts of reasons, professional and personal. In the present issue, for example, four of the five main articles were entirely unplanned for:

- a sociolinguistic and lexicographical bombshell from Jaan Lilles in Canada

- a powerfully (and sadly) thought-provoking piece from Pearl Ntlhakana on South Africa's languages

- Stephen Levey's intriguing glimpse of new usage in Wantok in Papua-New Guinea, where English is influencing its own offspring Tok Pisin

- and a detailed, ground-breaking essay on English as an international language for accountants, by Robert $\mathrm{H}$. Parker.

The only pre-planned main article is Marko Modiano's further response to invited comments on his first piece in ET58 (Apr 99). And, as Post \& (E)Mail indicates, his articles on a standard for English worldwide and the status of competent non-native users of the language continue to attract responses.

Selecting and arranging the content for 64 pages every quarter can be a delicate business, but actually filling the space at my desk in Cambridge has never been a problem. On this occasion, however, the filling is being done from afar, during a Januarythrough-March visiting professorship at the beautiful hillside campus of the Chinese University of Hong Kong - an undertaking in which electronic contact is more significant than ever. Wonder of wonders, however, the same editorial email address still applies: see across. During the gestation of this issue, I have been going through a steep learning curve on the rim of a China whose dual use of English and high tech is bursting all bounds - as may become clear in the later issues of the year 2000 .

Tom McArthur

The editorial policy of English Today is to provide a focus or forum for all sorts of news and opinion from around the world. The points of view of individual writers are as a consequence their own, and do not reflect the opinion of the editorial board. In addition, wherever feasible, ET generally leaves unchanged the orthography (normally British or American) and the usage of individual contributors, although the editorial style of the journal itself is that of Cambridge University Press. 